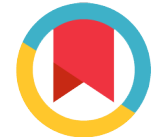

Check for updates

\title{
Association between cigarette smoking behavior and infertility in women: a case- control study
}

\author{
Mandana Sarokhani1', Yousef Veisani2 ${ }^{2}$, Akbar Mohamadi3, Ali \\ Delpisheh", Kourosh Sayehmiri5, ${ }^{*}$, Ashraf Direkvand-Moghadam ${ }^{6}$, \\ Mahshid Aryanpur?
}

\begin{abstract}
${ }^{1}$ Student Research Committee, Ilam University of Medical Sciences, Ilam, Iran ${ }^{2}$ Psychosocial Injuries Research Center, Ilam University of Medical Sciences, Ilam, Iran ${ }^{3}$ Student Research Committee, Ilam University of Medical Sciences, Ilam, Iran ${ }^{4}$ Department of Clinical Epidemiology, Ilam University of Medical Sciences, Ilam, Iran ${ }^{5}$ Psychosocial Injuries Research Center, Ilam University of Medical Sciences, Ilam, Iran ${ }^{6}$ Psychosocial Injuries Research Center, Ilam University of Medical Sciences, Ilam, Iran ${ }^{7}$ Tobacco Prevention and Control Research Center, National Research Institute of Tuberculosis and Lung Diseases, Masih Daneshvari Hospital, Shahid Beheshti University of Medical Sciences, Tehran, Iran
\end{abstract}

*For correspondence:

sayehmiri@razi.tams.ac.ir

Competing interests: The authors declare that no competing interests exist.

Received: 29 August 2017

Accepted: 02 October 2017

Published: 28 October 2017

Copyright The Author(s) 2017. This article is published with open access by BioMedPress

This article is distributed under the terms of the Creative Commons Attribution License (CC-BY 4.0) which permits any use, distribution, and reproduction in any medium, provided the original author(s) and the source are credited.

\section{Abstract}

Introduction: The effects of smoking on decreasing the chance of fertility in women have been acknowledged but some aspects, such as smoking behavior, are currently unclear. The present study aims to evaluate the relationship between smoking traits and infertility in women through a comparative study with fertile women. Methods: This case-control study was conducted on 350 women (177 infertile and 173 fertile) in MarchMay 2014. Sampling was performed in two phases. Demographic and reproductive data were collected by questionnaires- for demographics and the Fagerstrom Test for Nicotine Dependence (FTND)). The total score of questionnaires was ten. The participants were divided into 3 groups: "Low Nicotine" dependency (0-4), "Moderate Nicotine" dependency (5) and "High Nicotine" dependency (6-10). To examine the relationship between smoking and infertility, both the chi-square test and logistic regression tests were used. Results: Tobacco use in infertile women was greater than that for fertile women $(23.7 \%$ vs. $16.1 \%$, respectively, $\mathrm{P}=0.012)$; in fact, $16.7 \%$ of tobacco consumers had high nicotine dependency. Medium and low nicotine dependency were seen in $5.6 \%$ and $77.8 \%$ of tobacco consumers, respectively. Positive history of smoking increased the odds of being infertile (OR 2.88; $95 \% \mathrm{Cl}: 1.56-4.92)$ and risk for infertility was associated with low nicotine dependency $(\mathrm{OR} 3.12 ; 95 \% \mathrm{Cl}$ 1.16-8.09). 
Conclusion: Low and high nicotine dependency increased the risk of infertility. Considering the physical, mental, social and economic effects of infertility in society, the negative effects of smoking on fertility should be considered and/or included in the training package for health service providers.

\section{Keywords}

Cigarette, Infertility, Nicotine addiction, Smoking

\section{Introduction}

Infertility as a phenomenon is sometimes curable and sometimes incurable, leading to negative emotional impact on couples (Delpisheh et al., 2007; Direkvand-Moghadam et al., 2015; Direkvand-Moghadam et al., 2016; Sezgin et al., 2016). To date, about 10-15\% of all couples suffer from infertility (Sarvari et al., 2010). An increased prevalence of infertility around the world has caused worry in the general population. Efforts have been made to evaluate the factors affecting pregnancy outcomes (Sépaniak et al., 2006). Tobacco use is considered a high-risk behavior. Indeed, $30 \%$ of females and 35\% of males of reproductive age in the United States are addicted to tobacco smoking (The Practice Committee of the American Society for Reproductive Medicine, 2008). In fact, primary infertility and history of primary infertility have been reported in $3.6 \%$ and $1.7 \%$ of tobacco smokers, respectively (Delpishe et al., 2014).

A single cigarette contains 400 chemical compounds, some of which are toxic and carcinogenic. Nicotine, carbon monoxide, tar, arsenic, ammonia and hydrogen cyanide, are the ingredients in cigarettes, which additional can contribute to heart and lung injury. These substances have a great impact on the human reproductive system (Cooper and Moley, 2008). So far, several studies regarding the impact of tobacco on human fertility have been carried out; however, conflicting results have been reported.

Some of these studies have reported a negative impact of smoking on male and female fertility (Dechanet et al., 2011; Oyeyipo et al., 2011). Indeed, smokers are more likely to have fertility problems than non-smokers. If a user smokes for many years or smokes many cigarettes per day, the risk for fertility problems increases (Amirkhani et al., 2014; Kim et al., 2015). However, other studies have reported that there is no significant relationship between smoking and fertility outcomes in humans (de Jong et al., 2014).

Smoking causes damage to DNA and leads to reduced sperm quality and induction of male infertility (Ernst et al., 2012). Passive smoking also causes a decrease in sperm motility and interference in sperm acrosome function (Arabi and Moshtaghi, 2005). One study reported that tobacco exposure during 
pregnancy can cause long-lasting effects in the reproductive system (Håkonsen et al., 2014). One such effect is the increase in ovarian dysgenesis in women who are exposed to tobacco during their fetal period (Uzumcu et al., 2012). Additionally, chemicals in cigarette smoke may accelerate follicular depletion in smokers and fetal exposure to cigarettes (which can reduce testosterone levels in girls) (Delpisheh et al., 2008; Strohsnitter et al., 2008).

The impact on reducing the age of menopause onset may be due to the decrease of vitamin and mineral absorption (Hatch et al., 2011). According to one study, tobacco use likely increases infertility by 1.6-fold (Hatch et al., 2006). Berthiller and colleagues, however, reported that fertility did not decline in both male and female passive smokers (Louis et al., 2011; Oyeyipo et al., 2013).

In light of the inconsistent results of some studies in relation to the impact of tobacco use on fertility, the aim of this study was to investigate the relationship between cigarette smoking behavior and infertility in women. The Fagerstrom Test for Nicotine Dependence (FTND) was used to evaluate multifactorial factors comprising two or more distinct factors.

\section{Materials-Methods}

\section{Patients}

This case-control study was conducted on 350 women (177 infertile and 173 fertile) from March-May 2014. Sampling was conducted as a two-stage form. The first step was carried out by using the cluster sampling procedure; 6 private health centers were selected in different areas of llam City, Iran. Afterward, the samples were chosen by simple random sampling method. We calculated sample size ( $n$ ) from the formula for case control studies (below) and by default prevalence from a previous study (Moosazadeh et al., 2013), where is the z-score of 0.475 (1.96), is the prevalence of smoking in infertile women, and refers to no prevalence of smoking in infertile women.

$$
n=\frac{2 \times z_{\left(1-\frac{\alpha}{2}\right)}^{2}+z_{(1-\beta)}^{2}}{\log _{(O R)^{2}} \times P\left(P-P_{1}\right)}
$$

\section{Variable definitions}

In the current study, women were divided into two groups: fertile and infertile (current primary infertility, current secondary infertility, and never been pregnant). According to the World Health Organization (WHO) report, the cumulative consumption of 100 cigarettes (or similar cases using hookah or pipes) during one's life span can be used as a criterion for being considered a smoker in this study. Thus, individuals who smoked 100 cigarettes or used hookah/pipes were placed in the "smokers" group. 


\section{Inclusion and exclusion criteria}

Inclusion criteria for selection of cases were married women with both primary and secondary infertility. In this study, infertility was defined as married women with unprotected sexual intercourse for 12 months or more without pregnancy. Primary infertility was defined as infertility occurring in women without any previous pregnancy, and secondary infertility was defined as infertility in women that occurred after previous completed pregnancy. We excluded all menopausal women, those with any detectable anatomical abnormalities affecting their fertility, and those with non-signed informed consent forms. Control subjects were selected from the population at random but stratified based on age.

\section{Questionnaire}

We used the Fagerstrom Test for Nicotine Dependence (FTND) questionnaires for data collection. FTND is a standard instrument for assessing the intensity of physical addiction to nicotine (Heatherton et al., 1991). In this study, FTND was used to determine the amount of nicotine dependency in the case and control groups. This test has 6 questions, including the time of igniting the first morning cigarette, the best consumed cigarette during the day (i.e. best time to consume), the mean number of cigarettes smoked daily, the smoking manner during illness leading to hospitalization, and smoking in prohibited places. The scores of this test was 10 . Based on the obtained scores, participants were divided into 3 groups which were classified as "Low Nicotine" dependency (0-4), "Moderate Nicotine" dependency (5), and "High Nicotine" dependency (6-10). The demographic questionnaire contained questions about age, education, occupation of the woman (and her husband), social-economic status, duration of marriage, the type of contraception methods, age of first pregnancy, history of previous pregnancies, the period of time trying to have a child, and the cause of infertility.

\section{Ethical considerations}

This study was undertaken with approval from the Ethical Committee of Ilam University of Medical Sciences in Iran (code: ir.medilam.rec.1395.135). Informed consent was obtained from all participants before enrollment in the study.

\section{Statistical analysis}

The standard deviation (SD) was used to describe the data frequency, percent and mean. The association between infertility and smoking with qualitative variables was determined by using $X^{2}$, Fisher Exact test and Monte Carlo methods. Logistic regression model was applied to compute the odds ratio (OR) with $95 \%$ confidence interval $(95 \% \mathrm{Cl})$. A P-value less than.05 was considered to be significant. 


\section{Results}

In this case-control study, 350 female subjects (including 173 fertile and 177 infertile women) were enrolled. The mean age of fertile and infertile women were $20.79 \pm 3.51$ and $19.65 \pm 2.79$ years, respectively, with no significant difference $(P=0.157)$. Of the subjects, $70(20 \%)$ participants had the experience of smoking at least once in their life. The experience of tobacco use in infertile women was greater than in fertile women $(23.7 \%$ versus $16.1 \%$, respectively; $P=$ 0.012). The experience or attitude towards smoking for the fertile and infertile groups are presented in Table 1.

Table 1. Experience of study subjects toward Smoking

\begin{tabular}{|c|c|c|c|c|}
\hline \multirow{2}{*}{ History } & \multicolumn{2}{|c|}{ Groups } & \multirow{2}{*}{$\begin{array}{l}\text { Total } \\
\text { N (\%) }\end{array}$} & \multirow{2}{*}{ P-Value* } \\
\hline & Fertile $\mathbf{N}(\%)$ & Infertile N (\%) & & \\
\hline Positive & $28(16.1)$ & 42(23.7) & 70(20) & \multirow{2}{*}{0.012} \\
\hline Negative & $145(83.9)$ & $135(76.3)$ & $280(80)$ & \\
\hline
\end{tabular}

\section{Table 2. Relation of smoking and Fagerstrom Test variables in study subjects}

\begin{tabular}{|c|c|c|c|c|c|c|}
\hline \multirow{2}{*}{\multicolumn{2}{|c|}{ Variables }} & \multicolumn{2}{|c|}{ Fertile } & \multicolumn{2}{|c|}{ Infertile } & \multirow{3}{*}{$\begin{array}{c}\text { P-Value* }^{*} \\
0.015\end{array}$} \\
\hline & & \multirow{2}{*}{$\begin{array}{l}\mathbf{N} \\
2\end{array}$} & \multirow{2}{*}{$\begin{array}{c}\% \\
16.7\end{array}$} & \multirow{2}{*}{$\begin{array}{l}\mathbf{N} \\
4\end{array}$} & \multirow{2}{*}{$\begin{array}{c}\% \\
17.4\end{array}$} & \\
\hline \multirow{4}{*}{$\begin{array}{c}\text { Cigarettes smoked } \\
\text { daily } \\
\text { (Number per day) }\end{array}$} & $1-5$ & & & & & \\
\hline & $6-30$ & 0 & 0 & 6 & 26.1 & $<0.001$ \\
\hline & $31-60$ & 5 & 41.7 & 5 & 21.7 & 1.0 \\
\hline & $>60$ & 5 & 41.7 & 8 & 34.8 & 0.043 \\
\hline \multirow{4}{*}{$\begin{array}{l}\text { Age at first smoking } \\
\text { experience }\end{array}$} & $1-10$ & 10 & 76.9 & 16 & 66.7 & 0.674 \\
\hline & $11-20$ & 2 & 15.4 & 5 & 20.8 & 0.035 \\
\hline & $21-30$ & 0 & 0 & 2 & 8.3 & - \\
\hline & 31 & 1 & 7.7 & 1 & 4.2 & 1.0 \\
\hline \multirow{4}{*}{$\begin{array}{l}\text { When is the best time } \\
\text { for smoking? (Attitude) }\end{array}$} & Morning & 4 & 30.8 & 16 & 69.6 & 0.024 \\
\hline & Other times & 9 & 69.2 & 7 & 30.4 & 0.031 \\
\hline & During illness & 4 & 30.8 & 8 & 27.6 & 0.005 \\
\hline & More in morning & 3 & 23.1 & 7 & 25.9 & 0.833 \\
\hline
\end{tabular}


In Table 2, the smoking habits of the fertile and infertile groups were broken down into the following components: number of cigarettes smoked daily, age at first smoking experience, the best time to smoke during the day. Indeed, $26.1 \%$ of infertile women smoked 6-30 cigarettes daily; this number was significantly higher than for fertile women $(p=<0.001)$. This difference was also observed with 1-5 and 31-60 daily cigarettes but to a lower degree.

Among the smokers, $66.7 \%$ of infertile and $76.9 \% \%$ of fertile women obtained the first experience of smoking at the age of $<10$ years old but this difference was not significant $(p=0.674)$. When we compared infertile and fertile groups with regards to the best time to smoke during the day, the results indicated that infertile women smoked in mornings more than fertile women $(p=0.024)$.

The results of the Fagerstrom Test are shown in Table 3. "Low Nicotine" dependency was found to be more frequent in all study subjects than was "Moderate Nicotine" or "High Nicotine" dependency. Moreover, low nicotine dependency was significantly greater in infertile women $(p=0.012)$.

Table 3. Nicotine dependency based on Fagerstrom Test variables in study subjects

\begin{tabular}{|c|c|c|c|}
\hline \multirow{2}{*}{ Dependency } & \multicolumn{2}{|c|}{ Groups } & P-Value* \\
\cline { 2 - 4 } & Fertile N (\%) & Infertile N (\%) & 0.012 \\
\hline Low & $10(90.9)$ & $14(77.8)$ & 1.0 \\
\hline Moderate & $1(9.1)$ & $1(5.6)$ & 0.001 \\
\hline High & $0(0.0)$ & $3(16.7)$ & \\
\hline * was determined by $X^{2}$ & & & \\
\hline
\end{tabular}

Thus, the significant factors that predicted infertility are: smoking in the morning hours of the day, low dependency compared to moderate and high dependency, and positive history or experience of smoking (Table 4). A positive history of smoking increased the odds of being infertile (OR 2.88; 95\% Cl: 1.56- 4.92). Regarding the time of the first cigarette smoked during morning hours, it was found that for women who smoke their first cigarette immediately after morning wake-up, their infertility risk was 5.14 times more than that of other women $95 \%$ $\mathrm{Cl}$ : 1.17-22.48). The risk for infertility is associated with low nicotine dependency (OR 3.12; 95\% Cl: 1.16-8.09). 
Table 4. Logistic regression analysis of factors associated with infertility in smoker and nonsmoker women

\begin{tabular}{|c|c|c|c|c|}
\hline Factors & & S.E & OR (Cl 95\%)* & P-Value \\
\hline Constant & -0.251 & 0.50 & $2.12(1.77-16.15)$ & 0.002 \\
\hline $\begin{array}{l}\text { Smoking in morning } \\
\text { hours }\end{array}$ & 1.63 & 0.75 & $5.14(1.17-22.48)$ & 0.030 \\
\hline Low dependency & 2.72 & 1.03 & $3.12(1.16-8.09)$ & 0.043 \\
\hline $\begin{array}{l}\text { Positive history of } \\
\text { smoking }\end{array}$ & 3.18 & 0.98 & $2.88(1.56-4.92)$ & 0.008 \\
\hline
\end{tabular}

\section{Discussion}

This cross-sectional study aimed to examine the relationship between cigarette smoking behavior and infertility in women. Based on the results, $16.7 \%$ of tobacco consumers have high nicotine dependency. Moderate and low nicotine dependency was reported in $14.7 \%$ and $82.7 \%$ of tobacco consumers, respectively. The results showed that $20 \%$ of the participants in the study have mentioned a history of tobacco cigarette experience at least once. Despite the various harms that smoking causes to the health of the community, one-third of the world's population over 15 years old permanently smoke cigarettes (Sépaniak et al., 2006; Strohsnitter et al., 2008). The results of our current study also showed that the rate of nicotine dependency in infertile women was greater than that for fertile women.

The intake of nicotine has a dose-related effect which lead to delays in fertilization via effects on hormone production in females and early menopause (which reduces the length of fertility). The possibility of spontaneous abortion with pathologic mechanisms as a result of cigarette smoking is another dangerous outcome in female smokers (Weigert et al., 1999). Studies have shown that high levels of nicotine can induce cellular apoptosis of ovarian follicles, resulting in increased infertility in women consuming tobacco (Harlev et al., 2015; Uzumcu et al., 2012). On the other hand, other ingredients in cigarettes can affect the anatomy and function of the uterine tubes, causing increased infertility in tobacco consumers (Oyeyipo et al., 2014). However, in contrast to our findings, one study reported no significant relationship between smoking and fertility (Oyeyipo et al., 2013).

Based on the results of our study, most infertile women declared that the best consumed cigarettes occurred in the morning period. Our analysis reveals that infertile women have a great dependency on nicotine. Moreover, based on our 
results, $16 \%$ of infertile women have mentioned extreme dependency to nicotine, while none of the fertile women reported extreme dependency to nicotine. A laboratory study analyzed the impact of the different concentrations of nicotine on fertility in rats and showed that nicotine had a dose-dependent effect on fertility power (Louis et al., 2011).

There were some limitations in our study. Firstly, interpretations from this study should be considered with caution since the data was derived from selfreporting items on the questionnaires. Secondly, recall bias is a factor for most case-control studies; it was for our study as well. Finally, our study was limited to only those subjects who passed the selection criteria.

\section{Conclusion}

In summary, nicotine dependency increases the risk of infertility. In light of the effects of infertility on the physical, mental, social and the economic aspects in the community, training on the negative effects of tobacco consumption on fertility should be included in the educational packages designed for health care providers.

\section{Abbreviations}

DNA: Deoxyribonucleic Acid

FTND: Fagerstrom Test for Nicotine Dependence

OR: Odds ratio

\section{Aknowledgement}

This article is adapted from the research plan; the Research Committee of Ilam University of medical sciences, hereby we are pleased to thank the private obstetric and midwifery centers of Ilam city specifically Dr Maryam Nouri and Dr. Naier Hodaie who sincerely cooperated with us during the study period. We also express our appreciation and gratitude to the deputy of research and technology in Ilam University of Medical Sciences for financing the project.

\section{Financial support}

This project was financially supported by Psychosocial Injuries Research Center, Ilam University of Medical Sciences. 


\section{Author Contribution}

Study concept and design: MS, YV. Analysis and interpretation of data: AM, AD, AD-M. The drafting of the manuscript: YV, AD-M. Critical revision of the manuscript for important intellectual content: YV, KS, MA. Statistical analysis: YV, KS. Study supervision: KS. All authors approved the final manuscript.

\section{References}

Arabi, M., \& Moshtaghi, H. (2005). Influence of cigarette smoking on spermatozoa via seminal plasma. Andrologia, 37(4), 119-124. https://doi.org/10.1111/j. 1439-0272.2005.00664.x

Cooper, A. R., \& Moley, K. H. (2008). Maternal Tobacco Use and Its Preimplantation Effects on Fertility: More Reasons to Stop Smoking. Seminars in Reproductive Medicine, 26(02), 204-212. https://doi.org/10.1055/s-2008-1042959

de Jong, A. M. E., Menkveld, R., Lens, J. W., Nienhuis, S. E., \& Rhemrev, J. P. T. (2014). Effect of alcohol intake and cigarette smoking on sperm parameters and pregnancy. Andrologia, 46(2), 112-117. https://doi.org/10.1111/and.12054

Dechanet, C., Anahory, T., Mathieu Daude, J. C., Quantin, X., Reyftmann, L., Hamamah, S., ... Dechaud, H. (2011). Effects of cigarette smoking on reproduction. Human Reproduction Update, 17(1), 76-95. https://doi.org/10.1093/humupd/dmq033

Delpisheh, A., Topping, J., Reyad, M., Tang, A.-W., \& Brabin, B. J. (2007). Smoking exposure in pregnancy: Use of salivary cotinine in monitoring. British Journal of Midwifery, 15(4), 216-220. https://doi.org/10.12968/bjom.2007.15.4.23385

Delpisheh, A., Topping, J., Reyad, M., Tang, A., \& Brabin, B. J. (2008). Prenatal alcohol exposure, <em>CYP17</em> gene polymorphisms and fetal growth restriction. European Journal of Obstetrics, Gynecology, and Reproductive Biology, 138(1), 49-53. https://doi.org/10.1016/j.ejogrb.2007.08.006

Direkvand-Moghadam, A., Delpisheh, A., \& Direkvand-Moghadam, A. (2015). Effect of Infertility on Sexual Function: A Cross-Sectional Study. Journal of Clinical and Diagnostic Research : JCDR, 9(5), QC01-QC3.

Direkvand-Moghadam, A., Delpisheh, A., Montazeri, A., \& Sayehmiri, K. (2016). Quality of Life in Infertile Menopausal Women; Development and Psychometric of an Instrument. Journal of Clinical and Diagnostic Research : JCDR, 10(6), IC01-IC5.

Ernst, A., Kristensen, S. L., Toft, G., Thulstrup, A. M., Håkonsen, L. B., Olsen, S. F., \& Ramlau-Hansen, C. H. (2012). Maternal smoking during pregnancy and reproductive health of daughters: A follow-up study spanning two decades. Human Reproduction (Oxford, England), 27(12), 3593-3600. https://doi.org/10.1093/humrep/des337

Håkonsen, L. B., Ernst, A., \& Ramlau-Hansen, C. H. (2014). Maternal cigarette smoking during pregnancy and reproductive health in children: A review of epidemiological studies. Asian Journal of Andrology, 16(1), 39-49. https://doi.org/10.4103/1008-682X. $\underline{122351}$ 
Harlev, A., Agarwal, A., Gunes, S. O., Shetty, A., \& du Plessis, S. S. (2015). Smoking and Male Infertility: An Evidence-Based Review. The World Journal of Men's Health, 33(3), 143-160. https://doi.org/10.5534/wjmh.2015.33.3.143

Hatch, E. E., Troisi, R., Wise, L. A., Hyer, M., Palmer, J. R., Titus-Ernstoff, L., . . Hoover, R. N. (2006). Age at Natural Menopause in Women Exposed to Diethylstilbestrol in Utero. American Journal of Epidemiology, 164(7), 682-688. https://doi.org/10.1093/aje/ kwj257

Hatch, E. E., Troisi, R., Wise, L. A., Titus-Ernstoff, L., Hyer, M., Palmer, J. R., . . Kaufman, R. (2011). Preterm Birth, Fetal Growth, and Age at Menarche among Women Exposed Prenatally to Diethylstilbestrol (DES). Reproductive Toxicology (Elmsford, N.Y.), 31(2), 151-157. https://doi.org/10.1016/j.reprotox.2010.11.006

Heatherton, T. F., Kozlowski, L. T., Frecker, R. C., \& Fagerström, K. O. (1991). The Fagerström Test for Nicotine Dependence: A revision of the Fagerström Tolerance Questionnaire. British Journal of Addiction, 86(9), 1119-1127. https://doi.org/10.1111/ j.1360-0443.1991.tb01879.x

Louis, G. M. B., Schisterman, E. F., Sweeney, A. M., Wilcosky, T. C., Gore-Langton, R. E., Lynch, C. D., . . .. (2011). Designing prospective cohort studies for assessing reproductive and developmental toxicity during sensitive windows of human reproduction and development - the LIFE Study. Paediatric and Perinatal Epidemiology, 25(5), 413-424. https://doi.org/10.1111/j.1365-3016.2011.01205.x

Moosazadeh, M., Ziaaddini, H., Mirzazadeh, A., Ashrafi-Asgarabad, A., \& Haghdoost, A. A. (2013). Meta-analysis of Smoking Prevalence in Iran. Addiction \& Health, 5(3-4), 140153

Oyeyipo, I. P., Raji, Y., \& Bolarinwa, A. F. (2013). Nicotine alters male reproductive hormones in male albino rats: The role of cessation. Journal of Human Reproductive Sciences, 6(1), 40-44. https://doi.org/10.4103/0974-1208.112380

Oyeyipo, I. P., Raji, Y., \& Bolarinwa, A. F. (2014). Antioxidant profile changes in reproductive tissues of rats treated with nicotine. Journal of Human Reproductive Sciences, 7(1), 41-46. https://doi.org/10.4103/0974-1208.130823

Oyeyipo, I. P., Raji, Y., Emikpe, B. O., \& Bolarinwa, A. F. (2011). Effects of Nicotine on Sperm Characteristics and Fertility Profile in Adult Male Rats: A Possible Role of Cessation. Journal of Reproduction \& Infertility, 12(3), 201-207

Sarvari, A., Naderi, M., Heidari, M., Zarnani, A., Jeddi-Tehrani, M., Sadeghi, M., . . .. (2010). Effect of Environmental Risk Factors on Human Fertility. Journal of Reproduction \& Infertility, 11(4), 211-226.

Sépaniak, S., Forges, T., \& Monnier-Barbarino, P. (2006). Cigarette smoking and fertility in women and men. Gynecologie, Obstetrique \& Fertilite, 34(10), 945-949.

Sezgin, H., Hocaoglu, C., \& Guvendag-Guven, E. S. (2016). Disability, psychiatric symptoms, and quality of life in infertile women: A cross-sectional study in Turkey. Shanghai Jingshen Yixue, 28(2), 86-94.

Strohsnitter, W. C., Hatch, E. E., Hyer, M., Troisi, R., Kaufman, R. H., Robboy, S. J., . . . Noller, K. L. (2008). The Association between In Utero Cigarette Smoke Exposure and Age at Menopause. American Journal of Epidemiology, 167(6), 727-733. https:// doi.org/10.1093/aje/kwm351

The Practice Committee of the American Society for Reproductive Medicine (2008). Smoking and infertility. Fertility and Sterility, 90(5), S254-S9. https://doi.org/10.1016/ j.fertnstert.2008.08.035 
Uzumcu, M., Zama, A. M., \& Oruc, E. (2012). Epigenetic Mechanisms in the Actions of Endocrine-disrupting Chemicals: Gonadal Effects and Role in Female Reproduction. Reproduction in domestic animals, 47(s4), 338-347.

Weigert, M., Hofstetter, G., Kaipl, D., Gottlich, H., Krischker, U., Bichler, K., . . . Feichtinger, W. (1999). The Effect of Smoking on Oocyte Quality and Hormonal Parameters of Patients Undergoing In Vitro Fertilization-Embryo Transfer. Journal of Assisted Reproduction and Genetics, 16(6), 287-293. https://doi.org/10.1023/A: 1020496330424 